\title{
POSTOPERATIVE ATRIAL FIBRILLATION: AN OLD PROBLEM CRYING FOR NEW SOLUTIONS ${ }^{*}$
}

Lawrence L. Creswell, MD

Ralph J. Damiano, Jr, MD

n this issue of the Journal, Mueller and colleagues ${ }^{1}$ report on their experience with postoperative atrial arrhythmias in a series of 183 patients who underwent isolated single coronary artery bypass grafting (CABG) with the left internal thoracic artery placed to the left anterior descending coronary artery. The authors observed that the prevalence of postoperative atrial arrhythmias was similar, at approximately $18 \%$ to $22 \%$, for patients having conventional $\mathrm{CABG}$ and for those having beating-heart operations. With the development and growing acceptance of technologies that facilitate less invasive approaches for $\mathrm{CABG}$, several recent, but conflicting, reports have been published on the frequency of this complication. ${ }^{2-12}$ In light of an appreciable change in the current practice of $\mathrm{CABG}$, and the conflicting information regarding postoperative atrial fibrillation, it would be useful to reflect on what is presently known about this complication and the most appropriate direction for our future efforts in this area.

Large-scale longitudinal studies have demonstrated that atrial fibrillation is the most common arrhythmia in the general population. ${ }^{13,14}$ The prevalence of this arrhythmia increases with age, with a prevalence of less than $1 \%$ at age 50 but more than $9 \%$ to $10 \%$ at age $80 .{ }^{13}$ Other risk factors in the general population include congestive heart failure, valvular heart disease, hypertension, diabetes, and a history of myocardial infarction. Given these predisposing factors, it is not surprising that this arrhythmia is a common complication in the adult population having cardiac surgery.

Atrial arrhythmias have been recognized as a common postoperative complication since the earliest days of CABG. These arrhythmias include atrial fibrillation, atrial flutter, and paroxysmal atrial tachycardia. Clinical studies have reported a prevalence of $25 \%$ to $40 \%$ among patients undergoing $\mathrm{CABG}$, with a peak inci-

*For related article, see p. 683 .

From the Division of Cardiothoracic Surgery, Washington University School of Medicine, St Louis, Mo.

J Thorac Cardiovasc Surg 2001;121:638-41

Copyright (c) 2001 by The American Association for Thoracic Surgery

0022-5223/2001 $\$ 35.00+0 \quad \mathbf{1 2 / 1 / 1 1 4 3 4 7}$

doi: $10.1067 / \mathrm{mtc} .2001 .114347$ dence occurring between the second and fourth days after the operation. ${ }^{15}$ This rate is even higher for patients undergoing valve replacement, either alone or in combination with CABG. For most patients, postoperative atrial arrhythmias are a benign complication, without significant morbidity. Nonetheless, there is ample evidence that they are associated with adverse outcomes, including patient discomfort or anxiety, the need for extra medications or treatments, the possibility of thromboembolic complications, and both increased hospital length of stay and hospital costs. ${ }^{16-18}$ There are few data regarding the post-hospital discharge course of patients with this complication, but it is generally believed that the risk of this arrhythmia decreases substantially within the first month after surgery. It is important to remember that in an era of early hospital discharge, often on the third or fourth postoperative day, these arrhythmias may occur after discharge and patients should be counseled appropriately.

The treatment of patients with postoperative atrial arrhythmias has not been standardized despite many years of clinical experience and investigation. Directcurrent cardioversion is highly effective for restoring sinus rhythm in most patients, but this procedure is typically reserved for patients with hemodynamic instability. In clinical practice, most patients are treated medically for their arrhythmias. There are two goals of pharmacologic therapy: (1) control of the heart rate and (2) conversion to a sinus rhythm. Medications such as diltiazem, $\beta$-blockers, or digoxin can be used effectively to control the heart rate, and drugs such as sotalol, amiodarone, ibutilide, procainamide, and quinidine, among others, can be used to restore sinus rhythm. Each of these agents may be most appropriate for certain patient groups, and all require specific monitoring during treatment (ie, Q-T interval, serum levels). Because pharmacologic therapy and/or cardioversion are so effective, nearly all patients can be discharged in sinus rhythm. For patients in whom sinus rhythm cannot be restored, adequate heart rate control and anticoagulation with warfarin sodium (Coumadin) are appropriate.

The pathogenesis of postoperative atrial arrhythmias is not completely understood. On the basis of experimental models, an underlying electrophysiologic abnormality is a necessary substrate for these arrhythmias. ${ }^{19}$ 
A nonuniform dispersion of refractoriness in the atrial tissue can set up local areas of functional block. These can be established simply by the process of aging (ie, progressive fibrosis of the atrial tissue) or long-standing volume overload, but may also be affected by events inherent in conventional cardiac surgical procedures (ie, ischemia during cardioplegic arrest, cannulation technique) or by changes that might occur after any type of surgical procedure (ie, alterations in autonomic tone). Regardless of how the substrate is established, an initiating premature atrial contraction is also required to begin the arrhythmia. From a theoretical standpoint, patients undergoing beating-heart CABG would not be subject to some of these precipitating factors (ie, atrial ischemia, cannulation techniques) but would still be subject to others (ie, alterations in autonomic tone). Unfortunately, our limited knowledge of the pathogenesis and underlying mechanisms of these arrhythmias has precluded the development of specific therapies to prevent their occurrence.

A variety of strategies have been proposed over the years to reduce the frequency of postoperative atrial arrhythmias. Although numerous studies of pharmacologic agents have been reported, the results have often been conflicting. ${ }^{20-24}$ The most compelling evidence supports the use of $\beta$-blockers postoperatively to reduce the frequency of these arrhythmias. ${ }^{20}$ Moreover, $\beta$ blocker withdrawal should be avoided because this practice is associated with an increase in the frequency of these arrhythmias. The use of other drugs is more controversial. Used prophylactically, the administration of digoxin or supplementation with magnesium does not appear to be effective. ${ }^{21,22}$ Calcium channel blockers, particularly verapamil, can be associated with adverse hemodynamic effects and are not effective for this purpose. The prophylactic use of type Ia agents (ie, procainamide, quinidine) in this setting has not been studied extensively, and they are rarely used by surgeons. The use of type Ic antiarrhythmic agents (ie, sotalol, amiodarone) has shown promise for at least some patient subgroups in several recent small studies. Amiodarone, administered for several days before the operation, or sotalol, used in low doses postoperatively, both appear to reduce the frequency of postoperative atrial arrhythmias. ${ }^{23,24}$ Further studies are clearly needed in this area.

Nonpharmacologic strategies may also be useful for preventing this complication. A variety of pacing strategies have been proposed in the early postoperative period to reduce the number of premature atrial contractions, but these approaches have produced only limited success in reducing the prevalence of postoperative atrial arrhythmias. ${ }^{25}$ The maze procedure is very effective for preventing these arrhythmias, but the addition of this procedure carries a finite risk of additional morbidity and mortality and has been reserved for highly selected patients with preoperative chronic atrial fibrillation. Newer approaches involving a more limited "maze-like" procedure, including targeted isolation of anatomic substrates, such as the pulmonary veins, may have some applicability in the future ${ }^{26}$ if they can be made less invasive and easy to perform. However, their development awaits a clearer mechanistic understanding of the necessary substrate required for the initiation of these arrhythmias.

In the year 2000, up to $20 \%$ of all CABG operations were performed with a "less invasive" approach. Several approaches that avoid the use of cardiopulmonary bypass are currently available, including minimally invasive direct coronary artery bypass (MID$\mathrm{CAB}$ ) using a mini-thoracotomy incision, off-pump coronary artery bypass (OPCAB) using a conventional sternotomy incision, and endoscopic approaches. Each of these operations can be accomplished with the aid of a variety of stabilization devices, bypass conduits, and anesthetic techniques. On the basis of the technical details of these operations, this is obviously a heterogeneous group of patients. Not surprisingly, the literature is replete with conflicting information regarding the incidence of postoperative atrial arrhythmias after minimally invasive $\mathrm{CABG}$. In a retrospective, nonrandomized survey, Buffolo and colleagues ${ }^{2}$ reported significantly fewer arrhythmias (atrial and ventricular) among patients who underwent OPCAB. Chauhan and colleagues $^{3}$ reported a lower prevalence of postoperative atrial arrhythmias in a small number of patients who underwent MIDCAB procedures than among those who underwent conventional $\mathrm{CABG}$ procedures. Allen and colleagues ${ }^{4}$ reported no postoperative atrial arrhythmias in a small group of patients who underwent single-vessel redo CABG with the left internal thoracic artery to the left anterior descending coronary artery using a MIDCAB approach. Subramanian, McCabe, and Geller ${ }^{5}$ reported that postoperative atrial fibrillation developed in $8 \%$ of patients (14/185) undergoing a MIDCAB operation.

There are an equal number of negative studies showing no difference in the incidence of postoperative atrial arrhythmias. Cohn, Sirois, and Johnson ${ }^{6}$ reported a small case-control study in which there was no difference in the frequency of postoperative atrial arrhythmias for patients who underwent MIDCAB and those who underwent conventional CABG. Other "negative" studies were reported by Abreu, ${ }^{7}$ Saatvedt, ${ }^{9}$ Siebert, ${ }^{10}$ and their colleagues. Each of these studies involved 
small numbers of patients in the groups not having cardiopulmonary bypass. The small, retrospective, nonrandomized study by Mueller and colleagues ${ }^{1}$ in this issue of the Journal reports similar findings. In another retrospective review, Tamis-Holland and colleagues ${ }^{11}$ reported a lower frequency of postoperative atrial arrhythmias among patients undergoing MIDCAB procedures compared with those undergoing conventional CABG, but they attributed this finding to underlying differences in the two patient groups. Unfortunately, most of these studies were nonrandomized, retrospective case reports. All of these studies can be criticized for not comparing identical patient groups undergoing conventional versus less invasive CABG.

The most compelling evidence for a lower frequency of postoperative atrial arrhythmias comes from a recent prospective, randomized trial of 200 patients reported by Ascione and colleagues. ${ }^{12}$ In this study, the prevalence of postoperative atrial arrhythmias was $49 \%$ in the conventional CABG group but only $14 \%$ in the beating-heart group. However, a criticism of this study was the high incidence of arrhythmias in the conventional group and a nonuniform use of $\beta$-blockers.

Although the study by Mueller and colleagues ${ }^{1}$ in this issue of the Journal reports on a very small number of patients and lacks the statistical power to detect a meaningful difference in the rates of postoperative atrial arrhythmias between the patient groups, the authors' observations are important to help set the stage for further investigation. It is a common progression in our field that anecdotal accounts are often followed by small and then larger retrospective studies. It is obvious that the ideal study to settle the issue would be a prospective trial of conventional CABG versus less invasive $\mathrm{CABG}$, in which the development of postoperative atrial arrhythmias was an end point. Unfortunately, as many as 1000 patients per group would be needed to have sufficient statistical power to identify a $25 \%$ difference in the rates of postoperative atrial arrhythmias. This would be a monumental undertaking, but only rigorous prospective clinical investigation will resolve many of the outstanding issues related to the occurrence of postoperative atrial arrhythmias.

Real progress in this area will not occur until targeted laboratory investigation better elucidates the underlying mechanisms of postoperative atrial arrhythmias. After almost 50 years of open cardiac surgery, the prevention of one of the most common postoperative complications remains elusive. Postoperative atrial arrhythmias remain a vexing clinical problem crying for meticulous, carefully controlled laboratory and clinical research. Ideally, cardiac surgeons will rise to this chal- lenge in the coming decade and finally develop an effective therapy based on a firm mechanistic foundation to prevent this common cause of patient morbidity after cardiac surgery.

Received for publication Jan 9, 2001; accepted for publication Jan 10, 2001.

Address for reprints: Ralph J. Damiano, Jr, MD, John M. Shoenberg Professor of Surgery, Chief of Cardiac Surgery, Washington University School of Medicine, Campus Box 8234, Suite 3108 Queeny Tower, One Barnes-Jewish Hospital Plaza, St Louis, MO 63110.

\section{REFERENCES}

1. Mueller XM, Tevaearai HT, Ruchat P, Stumpe F, von Segesser LK. Did the introduction of minimally invasive technique change the incidence of atrial fibrillation after single internal thoracic artery-left anterior descending artery grafting? J Thorac Cardiovasc Surg 2001;121:683-8.

2. Buffolo E, de Andrade JCS, Branco JNR, Teles CA, Aguiar LF, Gomes WJ. Coronary artery bypass grafting without cardiopulmonary bypass. Ann Thorac Surg 1996;61:63-6.

3. Chauhan VS, Gill I, Woodend KA, Tang AS. Lower incidence of atrial fibrillation after minimally invasive direct coronary artery bypass surgery (MIDCAB) than bypass surgery (CABG) [abstract]. Circulation 1997;46(Suppl):I-263.

4. Allen KB, Matheny RG, Robison RJ, Heimansohn DA, Shaar CJ. Minimally invasive versus conventional reoperative coronary artery bypass. Ann Thorac Surg 1997;64:616-22.

5. Subramanian VA, McCabe JC, Geller GM. Minimally invasive direct coronary artery bypass grafting: two-year clinical experience. Ann Thorac Surg 1997;64:1648-55.

6. Cohn WE, Sirois CA, Johnson RG. Atrial fibrillation after minimally invasive coronary artery bypass grafting: a retrospective, matched study. J Thorac Cardiovasc Surg 1999;117:298-301.

7. Abreu JE, Reilly J, Salzano RP, Khachane VB, Jekel JF, Clyne CA. Comparison of frequencies of atrial fibrillation after coronary artery bypass grafting with and without the use of cardiopulmonary bypass. Am J Cardiol 1999;83:775-6.

8. Asher CR, DiMengo JM, Arheart KL, Weber MM, Grimm RA, Blackstone EH, et al. Atrial fibrillation early postoperatively following minimally invasive cardiac valvular surgery. Am J Cardiol 1999;84:744-7.

9. Saatvedt K, Fiane AE, Sellevold O, Nordstrand K. Is atrial fibrillation caused by extracorporeal circulation? Ann Thorac Surg 1999;68:931-3.

10. Siebert J, Rogowski J, Jagielak D, Anisimowicz L, Lango R, Narkiewicz M. Atrial fibrillation after coronary artery bypass grafting without cardiopulmonary bypass. Eur J Cardiothoracic Surg 2000;17:520-3.

11. Tamis-Holland JE, Homel P, Durani M, Iqbal M, Sutandar A, Mindich BP, et al. Atrial fibrillation after minimally invasive direct coronary artery bypass surgery. J Am Coll Cardiol 2000;36:1884-8.

12. Ascione R, Caputo M, Calori G, Lloyd CT, Underwood MJ, Angelini GD. Predictors of atrial fibrillation after conventional and beating heart coronary surgery: a prospective, randomized study. Circulation 2000;102:1530-5. 
13. Feinberg WM, Blackshear JL, Laupacis A, Kronmal R, Hart RG. Prevalence, age distribution, and gender of patients with atrial fibrillation: analysis and implications. Arch Int Med 1995; 115:469-73.

14. Benjamin EJ, Levy D, Vaziri SM, D'Agostino RB, Belanger AJ, Wolf PA. Independent risk factors for atrial fibrillation in a population-based cohort. JAMA 1994;271:840-4.

15. Aranki SF, Shaw DP, Adams DH, Rizzo RJ, Couper GS, VanderVliet M, et al. Predictors of atrial fibrillation after coronary artery surgery: current trends and impact on hospital resources. Circulation 1996;94:390-7.

16. Creswell LL, Schuessler RB, Rosenbloom M, Cox JL. Hazards of postoperative atrial arrhythmias. Ann Thorac Surg 1993;56:539-49.

17. Almassi GH, Schowalter T, Nicolosi AC, Aggarwal A, Moritz TE, Henderson WG, et al. Atrial fibrillation after cardiac surgery: A major morbid event? Ann Surg 1997;276:300-6.

18. Kowey PR, Dalessandro DA, Herbertson R, Briggs B, Wertan MAC, Rials SJ, et al. Effectiveness of digitalis with or without acebutolol in preventing atrial arrhythmias after coronary artery bypass surgery. Am J Cardiol 1997;79:1114-7.

19. Sato S, Yamauchi A, Schuessler RB, Boineau JP, Matsunaga Y, Cox JL. The effect of augmented atrial hypothermia on atrial refractory period, conduction, and atrial flutter/fibrillation in the canine heart. J Thorac Cardiovasc Surg 1992;104:297-306.

20. Kowey PR, Taylor JE, Rials SJ, Marinchak RA. Meta-analysis of the effectiveness of prophylactic drug therapy in preventing supraventricular arrhythmia early after coronary artery bypass grafting. J Am Coll Cardiol 1992;69:963-5.

21. Tyras DH, Stothert JC, Kaiser GC, Barner HB, Codd JE, Willman VL. Supraventricular tachyarrhythmias after myocardial revascularization: a randomized trial of prophylactic digitalization. J Thorac Cardiovasc Surg 1979;77:310-4.

22. Parikka H, Toivonen L, Pellinen T, Verkkala K, Jarvinen A, Nieminen MS. The influence of intravenous magnesium sulphate on the occurrence of atrial fibrillation after coronary artery bypass operation. Eur Heart J 1993:14:251-9.

23. Daoud EG, Strickberger SA, Man KC, Goyal R, Deeb GM, Bolling SF, et al. Preoperative amiodarone as prophylaxis against atrial fibrillation after heart surgery. $N$ Engl $J$ Med 1997;337:1785-91.

24. Parikka H, Toivonen L, Heikkila L, Virtanen K, Jarvinan A. Comparison of sotalol and metoprolol in the prevention of atrial fibrillation after coronary artery bypass surgery. J Cardiovasc Pharmacol 1998;31:67-73.

25. Yu W, Chen S, Tai C, Feng A, Chang M. Effects of different atrial pacing modes on atrial electrophysiology: implicating the mechanisms of biatrial pacing in prevention of atrial fibrillation. Circulation 1997;96:2992-6.

26. Sie HT, Beukema WP, Misier ARR, Elvan A, Ennema JJ, Haalebus MM, et al. Radiofrequency modified MAZE in patients with atrial fibrillation undergoing concomitant cardiac surgery. J Thorac Cardiovasc Surg. In press.

\section{Availability of Journal Back Issues}

As a service to our subscribers, copies of back issues of Surgery for the preceding 5 years are maintained and are available for purchase from Mosby until inventory is depleted. The following quantity discounts are available: $25 \%$ off on quantities of 12 to 23 , and one third off on quantities of 24 or more. Please write to Mosby Subscription Customer Service, 6277 Sea Harbor Dr, Orlando, FL 32887, or call (800) 654-2452 or (407) 345-4000 for information on availability of particular issues. If unavailable from the publisher, photocopies of complete issues may be purchased from Bell \& Howell, 300 N Zeeb Rd, Ann Arbor, MI 48106 (313)7614700 or (800) 521-0600. 